\title{
Mathematical modelling in primary schools-advanced topics at elementary level
}

Natalija Budinski

\section{Introduction}

Development of modern technology and industry makes mathematical modelling undeniably irreplaceable in many fields, such as environment or scientific computation (Quarteroni, 2009). According to Meerscshaert (2007), figurativelly speaking, mathematical modeling is joining mathematics and the rest of the world. Due to mathematical modelling various aspects of connection to the real world, it could be described in the language of science. Its importance is in being the third pillar of science and engineering, beside theoretical analysis and experimentation. Mathematical modelling starts with examination of basic information about the problem, continues with construction of mathematical models, and finishes with the solutions of the problem in the real-world sphere. Also, it is particularly important that every model need to be verified.

It is evident that mathematical model is central part of mathematical modelling. There are different definitions of models that could represent real-world situation. One of the most general division is to four broad categories: deterministic, stochastic, empirical and mechanistic (Marion, 2008). Deterministic models produce the same results for the fixed beginning values, while stochastic models produce various results which depend on the actual values. Empirical models describe how things work by relating independent and dependent variables, and empirical models are based on statistical regressions and data. There is also division of models depending on 
the mathematics and presentations, such as arithmetic, algebraic-analytic, graphical, geometrical, or combined. Models can be also equations or computer codes. For example, the strength of earthquakes is measured with the Richter's scale, which use logarithm. Magnitude of the earthquake can be calculated by formula (1)

$$
M(x)=\log \left(\frac{x}{x_{0}}\right)
$$

where $\mathrm{M}$ is the magnitude of earthquake, $x$ is the measure of the amplitude of earthquake wave and $x_{0}$.

\section{Mathematical modelling in education}

The mathematical modelling significantly came into the educational focus in recently years.

In this paper we elaborate how can mathematical modelling be applied in the younger students' mathematical education in order to introduce students with the notion of function. The described example is applied in the primary school "Petro Kuzmjak" in Ruski Krstur in Serbia, with students 10-11 years old. Mathematical curriculum for the primary school students propose mathematical topics such as: number and its graphical representation, fractions, calculations (addition, subtraction, multiplication and division), equations and inequalities, word problems, measures, area of square, rectangle, and cube. There is also a recommendation that students could be introduced to functions trough real life examples in order to get knowledge about variables. Formally, content related to function is introduced to students age 13-14 years old in upper primary level school, and starts with linear function.

Significance of mathematical modelling is related to the potential of learning and teaching mathematics based on mathematical modelling and developing students' competences, and in our case, it was chosen as a teaching method. Mathematical modelling helps to connect real-world situations and mathematical concepts. Students learn to understand and decide about real-world problems the importance of mathematics as a tool for solving problems and giving answers to the relevant questions is highlighted during mathematical modelling activities in the classroom. Such activities are helpful in developing transferable skills that students could apply in other subjects and situations.

Blomhoj \& Jensen (2003) identify six competences related to the mathematical modelling: formulation of the problem, recognition of the rele- 


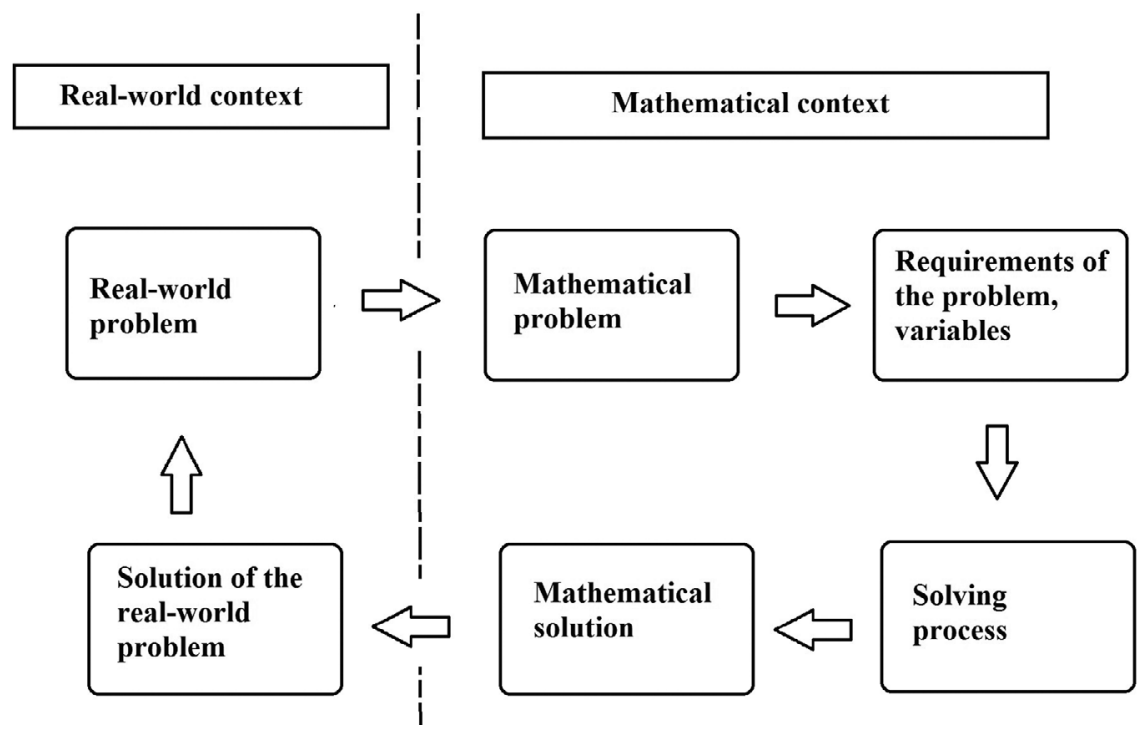

Figure ir: Mathematical modelling cycle in the educational settings

vant information, transition from real-world to mathematical context, use of mathematical methods, interpretation of mathematical results in the real-world context and evaluation or verification of the problem. Those competences are developing trough mathematical modelling phases.

The visual representation of the mathematical modelling application in the classroom can be seen in Figure 11 (Budinski \& Milinkovic, 2018). It can be seen how real-world and mathematical context could be connected through mathematical modelling phases. The transition from one phase to the other phase requires different kinds of cognitive activities, such as analysing, constructing, simplifying, structuring, mathematical working, interpreting, validating, and exploring (Blum \& Leis, 2007).

Mathematical modelling in the classroom begins with the starting point of situation or problem that needs the solution. Further step is to connect real-situations and mathematical content and producing a mathematical model. That phase is known as mathematization. According to Lukac \& Sekerak (2013), mathematization consider transition from the real-world to mathematical context. At the end, the mathematical model must be verified and interpreted in the real-world context. 


\section{Mathematical modelling in Primary School}

Mathematical modelling can be applied at all levels of education, but even though it is the case, (Diezmann et al., 2002; Doerr \& English, 2003) it is not much applied in primary schools and on the basic level of education. There is some research that shows that mathematical modelling can be effectively applied for developing mathematical competences in engaging and complex, but meaningful activities with primary school students (Doerr \& English, 2003).

In our study we used mathematical modelling as a base for teaching young students (age 1o years) different mathematical concepts: from basic mathematical calculating operation to the beginnings of one of the most important mathematical notion such as function. Learning mathematical operation and calculation is usual to connect with real-world context, but functions are not that common topic in primary schools, since that is an advanced concept. The idea for our study to introduce young learners with functions come from the fact that functions are one the most important mathematical concepts, but also a mathematical concept that is hard to grasp for students.

In order to introduce students in the elementary school (9-10 years old) to concepts of function we explored the possibilities of mathematical modelling application. We have applied mathematical modelling-based lessons in order to convey to students' different mathematical concepts and finally the mathematical concept of functions. The duration of the research was one year on the sample of 70 students in several primary schools in Bosnia and Herzegovina.

One of the modelling examples that was presented to students in order to highlight the concept of function was based on the real-world situation of population. For the purpose of the mathematical modelling we took the real-life situation of the population change. The real-life situation was a story about a village and its inhabitants. The task offered the information about population gender and age structure. It was written in the form of story. The first step was to understand the real-world situation and information given in the text. The text hide problems that students needed to solve. Problems were in the form of the unfinished sentences or visual representation of information from the text. In Figure 12 we can see the graphical representation of solution of the real-world problem where students needed to find and represent number of boys and girls in the one class in the village school. 


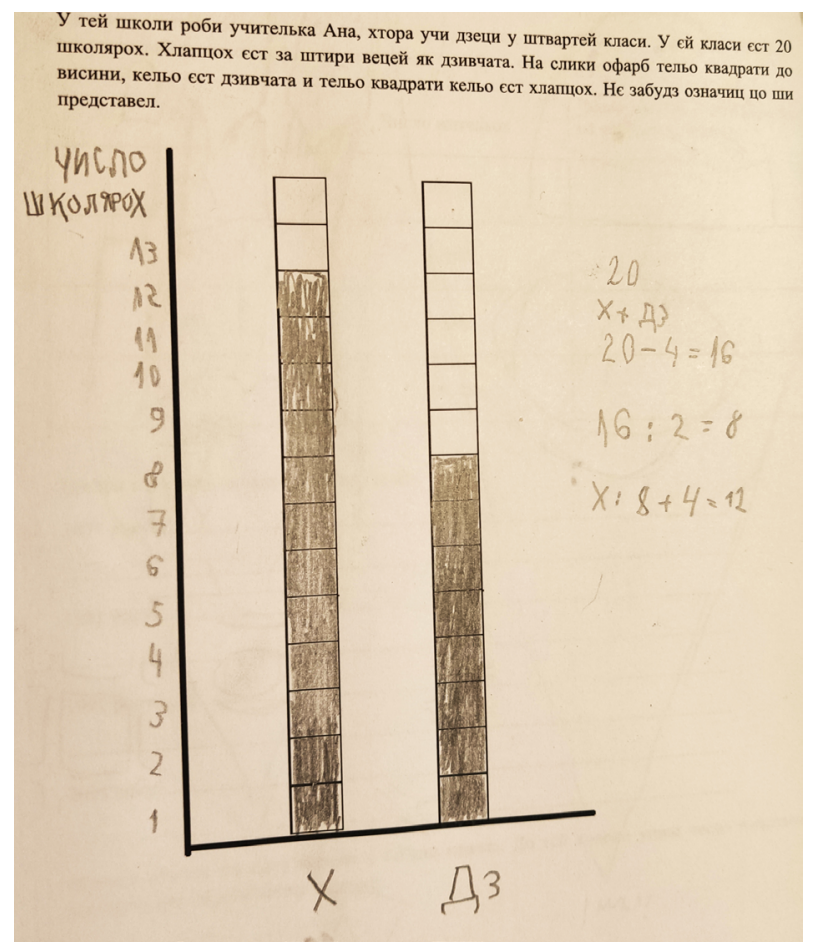

Figure 12: Solution of the real-world problem and its graphical representation

Following and solving tasks students were gradually guided to the solution of the main problem of the real-world situation which was to predict the population of the village in the future. Accordingly, to students age, the main problem required answer if the population of the village increase or decrease. Students needed to discuss dependence of the values, which in this case were time and number of inhabitants. This kind of activities helped students to verbally articulate relationship between variables in the problem of population in a village. Also, students graphically represented relationships between variables which they recognized in everyday situation. Modelling activities enabled students to have different kinds of experience, beside learning mathematics, such as dealing with problem of population or migration. According to their reactions, students liked activities and actively participated. During the solving tasks, they have many questions and issues since they never experienced this kind of activities. 


\section{Conclusions}

It is inevitable that teaching strategies need to be changed since we need students to be more creative, flexible and research oriented. They need to know how to solve problems that are not typical tasks from textbooks. The tasks based on mathematical modelling help students to learn how to work with data, how to represent them and draw conclusions. Beside that they could observe the dependence between the variables.

\section{Literature}

Blum, Werner and Leis, Dominik. "How do students' and teachers deal with modelling problems?" In: Haines, C. et al. (Eds), Mathematical Modelling: Education, Engineering and Economics. Chichester: Horwood, (2007): 222-231.

Budinski, Natalija and Milinković, Dragica. "Multidisciplinary approach in teaching mathematics in primary education". Нова школа, Часопис за теорију и праксу савремене школе и предшколства, XIII (1), (2018): 42-49.

Diezmann, Carmel, Watters, James and English, Lyn. "Teacher behaviors that influence young children's reasoning”, Proceedings 27th Annual Conference of the International Group for the Psychology of Mathematics Education 2, pp. 289-296, Norwich, UK.

Doerr, Helen and English, Lyn. 2003. "A Modeling Perspective on Students' Mathematical Reasoning about Data", Journal of Research in Mathematics Education, 34(2), (2002): 110-136.

Marion, Glenn. "An Introduction to Mathematical Modeling", Bioinformatics and Statistics, Scotland, 2008.

Meershart, Mark. "Mathematical Modeling", 3rd Academic Press, Inc. Orlando, FL, USA, 2007.

Lukac, Stanislav and Sekerák, Jozef. "Formation of the mathematical modeling competence using digital technologies". 265-269. 10.1109/ICETA.2013.6674441, 2013.

Quarteroni, Alfio. "Mathematical Models in Science and Engineering", Notices of AMS, 56(1), (2009): 10-19. 